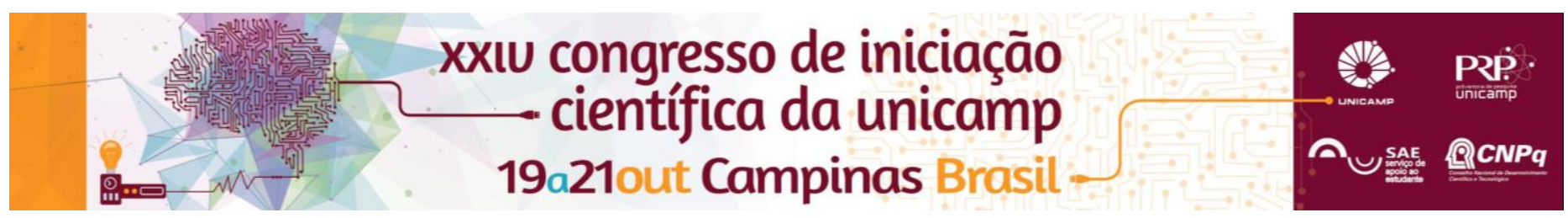

\title{
Codeposição de molibdênio utilizando ferro e cobalto para formação de ligas metálicas
}

\author{
Flávio Cosenza Veiga Barbosa*, Ambrósio Florêncio de Almeida Neto.
}

\section{Resumo}

Neste trabalho foram sintetizadas e caracterizadas ligas metálicas binárias, constituídas pelo molibdênio e utilizando ferro e cobalto como metais indutores, para essa eletrodeposição. As ligas metálicas obtidas foram caracterizadas por Difração de raios X e Microscopia Eletrônica de Varredura com EDX. Os resultados mostraram que o ferro foi um metal capaz de induzir a deposição do molibdênio, enquanto que o cobalto não se apresentou apropriado para esse fim.

\section{Palavras-chave:}

Ligas metálicas, molibdênio, corrosão.

\section{Introdução}

De maneira geral, a corrosão é um processo resultante da ação do meio sobre um determinado material, deteriorando este. É um fenômeno químico causado por reações de oxirredução, intimamente ligado aos metais. Como a corrosão causa a destruição total, parcial, superficial e estrutural dos materiais, do ponto de vista econômico, pode causar prejuízos com custos extremamente elevados em processos industriais, além de poder causar acidentes, colocar em risco a vida humana, contaminar e poluir o ambiente ${ }^{(1)}$. Assim sendo, este trabalho objetiva estudar e avaliar a eletrodeposição de ligas metálicas constituídas pelos metais molibdênio e ferro ou molibdênio e cobalto.

\section{Resultados e Discussão}

Os banhos eletrolíticos foram constituídos de molibdato de sódio, $\mathrm{Na}_{2} \mathrm{MoO}_{4}$, sal fonte de molibdênio, sulfato de Ferro, $\mathrm{FeSO}_{4}$, sal fonte de ferro e citrato de amônio, $\left(\mathrm{NH}_{4}\right)_{2} \mathrm{C}_{6} \mathrm{H}_{6} \mathrm{O}_{7}$ 0,15 mol/L, para complexar o metal ferro. Outros reagentes foram utilizados, como por exemplo: $\mathrm{Na}_{2} \mathrm{~B}_{4} \mathrm{O}_{7} 3,75.10^{-2} \mathrm{~mol} / \mathrm{L}$, para a partir deste obter uma liga amorfa; 1 -dodecilsulfato- $\mathrm{Na} 1,04.10^{-4} \mathrm{~mol} / \mathrm{L}$, para que - $\mathrm{H}_{2}$ liberado durante a eletrodeposição se desprenda rapidamente da solução, evitando a formação de bolhas na liga metálica e $\left(\mathrm{NH}_{4}\right)_{2} \mathrm{SO}_{4} 0,13 \mathrm{~mol} / \mathrm{L}$, para dar maior estabilidade ao banho. Os banhos para obter a liga de Co-Mo utilizaram sulfato de cobalto, $\mathrm{CoSO}_{4}$. Para que as eletrodeposições fossem realizadas, a densidade de corrente elétrica foi de $400 \mathrm{~mA} / \mathrm{cm}^{2}$, a rotação catódica $10 \mathrm{rpm}$, a temperatura $45^{\circ} \mathrm{C}$ e o pH 8 . Na Tabela 1 temse o planejamento experimental utilizado.

Tabela 1. Níveis reais e codificados das variáveis do planejamento fatorial $2^{2}$.

\begin{tabular}{|c|c|c|c|c|}
\hline \multicolumn{2}{|c|}{ Níveis } & -1 & 0 & +1 \\
\hline \multirow{2}{*}{ Variáveis } & $\mathrm{C}_{\mathrm{Fe}}(\mathrm{mol} / \mathrm{L})$ & 0,05 & 0,1 & 0,15 \\
\cline { 2 - 5 } & $\mathrm{C}_{\mathrm{Mo}}(\mathrm{mol} / \mathrm{L})$ & 0,1 & 0,2 & 0,3 \\
\hline
\end{tabular}

As eficiências de deposição obtidas nas eletrodeposições da liga de Fe-Mo foram baixas. Todavia, essas ligas apresentaram boa aderência e homogeneidade. As ligas foram caracterizadas por Difração de Raios X (DRX), microscopia eletrônica de varredura e análise química por Energia Dispersiva de Raios X (EDX).

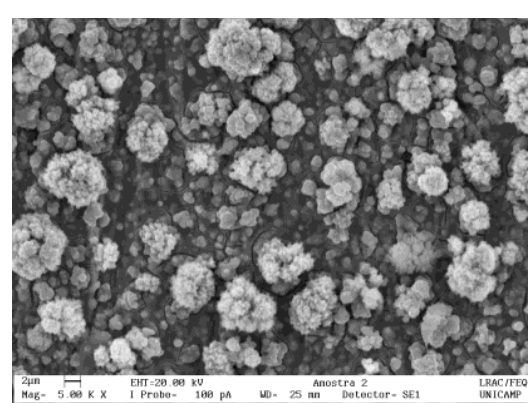

Figura 1. Superfície da liga de Fe-Mo, com ampliação de 5000 vezes.

Analisando a imagem da Figura 1, verificou-se a presença de três fases distintas. Uma das fases identificadas é a própria liga de $\mathrm{Fe}-\mathrm{Mo}$. As outras fases podem ser produtos da oxidação do ferro e/ou molibdênio. A análise química das ligas se deu através dos dados gerados por EDX, que permitiram quantificar as massas de ferro e molibdênio depositadas em cada liga metálica. Os resultados de DRX geraram três picos característicos bem definidos, a partir dos quais se conclui que as ligas apresentaram estrutura cristalina.

Também foram realizadas eletrodeposições no intuito de sintetizar e analisar ligas metálicas de Co-Mo nas mesmas condições experimentais que as ligas de $\mathrm{Fe}-\mathrm{Mo}$, substituindo-se o $\mathrm{FeSO}_{4}$ por $\mathrm{CoSO}_{4}$ no banho eletrolítico. Porém, as ligas de Co-Mo apresentaram eficiências extremamente baixas, sem homogeneidade e aderência, evidenciando que o ferro é um metal mais apropriado para formar uma liga com o molibdênio que o cobalto, nas condições experimentais avaliadas.

\section{Conclusões}

As ligas de Fe-Mo apresentaram estrutura cristalina bem definida, bem como a presença de três fases distintas em sua composição. Conclui-se que o ferro é um metal mais adequado para a liga de molibdênio que o cobalto.

\section{Agradecimentos}

Ao $\mathrm{PIBIC} / \mathrm{CNPq}$

Nunes, L.P.; Lobo, A.C.O. Pintura industrial na proteção anticorrosiva. Rio de Janeiro: Livros Técnicos e Científicos, 1990. 